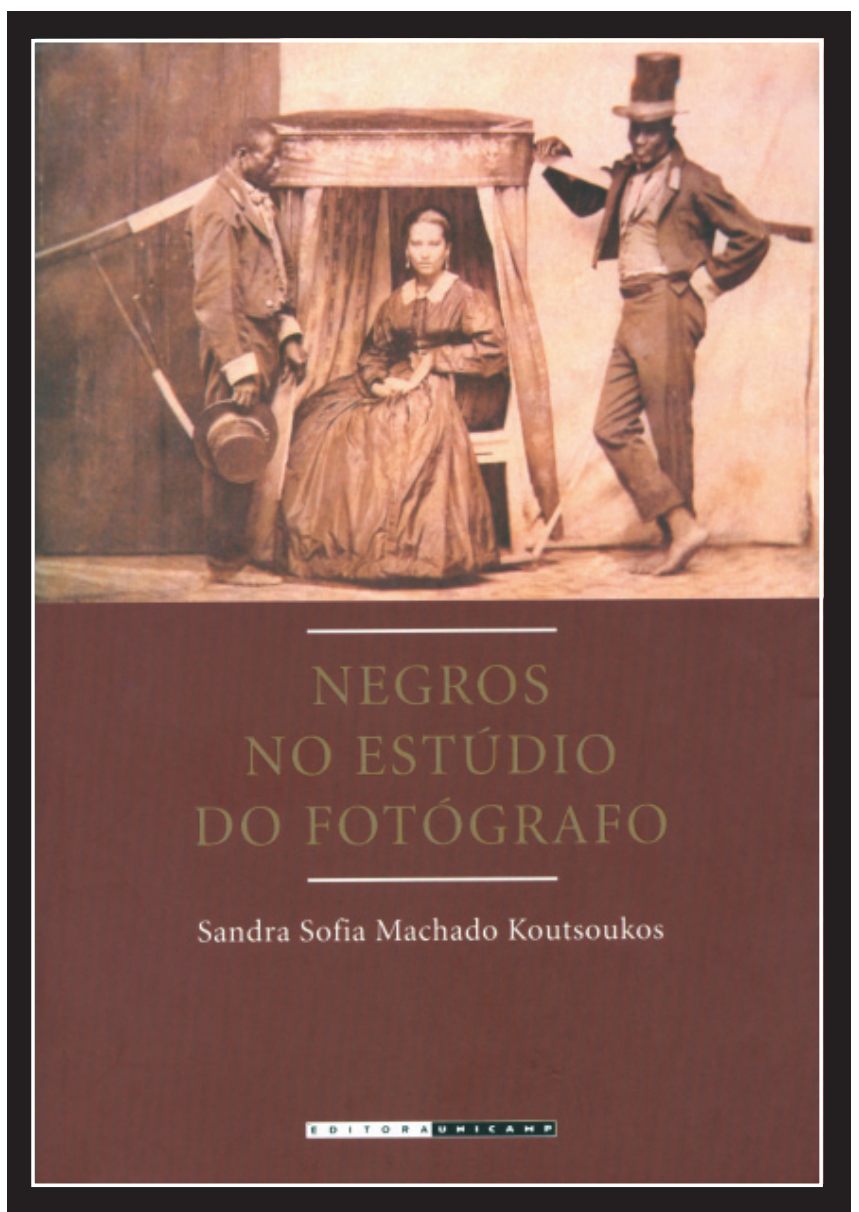

Negros no estúdio do fotógrafo: Brasil, segunda metade do século XIX, de Sandra Sofia Machado Koutsoukos. São Paulo: Editora da Unicamp, 2010, 360 p. 


\title{
Fotografia e escravidão: a segunda metade do século XIX contada por imagens
}

Photography and slavery: the second half of the XIX century told by images

\author{
Renata de Paula dos Santos*
}

Estudar as representações e autorrepresentações imagéticas dos negros africanos e brasileiros é o objetivo de Sandra Sofia Machado Koutsoukos em Negros no estúdio do fotógrafo: Brasil, segunda metade do século XIX (Editora da Unicamp, 2010, 360 páginas). O livro é uma adaptação da tese de doutorado defendida pela autora junto ao Programa de Pós-Graduação em Multimeios da Universidade Estadual de Campinas (Unicamp).

A publicação é uma revisita à história da escravidão nacional e ao princípio da fotografia no país. Sandra Koutsoukos reuniu neste trabalho imagens de importantes acervos brasileiros, como o Arquivo Nacional, a Fundação Biblioteca Nacional, a Fundação Joaquim Nabuco de Pesquisas Sociais (Fundaj), o Museu Paulista, o Instituto Moreira Salles e o Serviço do Patrimônio Histórico e Artístico Nacional (SPHAN).

Por se tratar inicialmente de uma tese de doutoramento, o texto conta com nomes referenciais para o estudo da fotografia. Destacam-se entre os teóricos Boris Kossoy, Roland Barthes, Walter Benjamin, Maria Eliza Linhares Borges, Pierre Bourdieu, Gisèle Freund e o colecionador George Ermakoff. Para retratar as características da população negra no período da escravidão, a autora citou Nelson Aguilar, Sidney Chalhoub, José Alípio Goulart e Lilia Moritz Schwarcz, entre outros. Os referenciais de pesquisa contemplam ainda uma infinidade de materiais do século XIX, como manuais de fotografia, livros de viajantes, documentos, jornais, revistas, teses e textos de medicina.

\footnotetext{
* Graduada em Comunicação Social - Jornalismo pela Universidade Estadual de Londrina (UEL). Especialista em Comunicação Popular e Comunitária e mestranda em Comunicação pela mesma instituição. Bolsista da CAPES. E-mail: renatapstos@hotmail.com
} 
Sandra Koutsoukos inicia a narrativa com um breve histórico da fotografia. A primeira fixação de imagens reais em um suporte data de 1839. A invenção, batizada de daguerreótipo, foi desenvolvida em Paris, por Louis Jacques Mandé Daguerre. No entanto, experimentações parecidas e com a mesma finalidade eram realizadas em outras partes do mundo. No Brasil, tentativas de fixar situações reais em um suporte foram desenvolvidas na Vila de São Carlos, atual Campinas, por Antoine Hercule Romuald Florence (1804-1879).

Durante os primeiros anos de utilização, o daguerreótipo produzia imagens de baixa qualidade. O longo tempo de exposição necessário para a fixação dos registros exigia dos personagens muita paciência. A autora destaca que era preciso muitas vezes parecer morto (imóvel) no estúdio para aparecer vivo nas imagens. Em virtude do longo período para tomada, alguns estúdios fotográficos possuíam aparelhos para auxiliar na manutenção da postura dos personagens.

Foi na década de 1850 que a fotografia se popularizou na Europa com a impressão dos registros em papel (o que resultou na queda do custo final das fotografias) e invenção do negativo (possibilidade de imprimir várias cópias). Já do outro lado do oceano, no Brasil, Dom Pedro II foi um dos primeiros incentivadores da fotografia ainda na década de 1840 , mas a disseminação da técnica ocorreu cerca de vinte anos depois.

Com o barateamento dos custos, a fotografia tornou-se acessível a parcelas menos favorecidas da população. Sandra Koutsoukos destaca que, com o passar do tempo, houve um processo de padronização da autoimagem e da representação do outro. Nesta perspectiva, cita que os grupos sociais mais modestos frequentemente se espelhavam nas classes mais ricas no momento do clique. A fotografia propiciou, assim, registros imagéticos que não condiziam diretamente com a realidade. Durante as primeiras décadas de produção fotográfica, uma série de manuais foi publicada com o intuito de auxiliar os iniciantes na técnica.

Em meados da década de 1860 eram comuns as figuras dos fotógrafos viajantes e itinerantes. Estes profissionais percorriam os vilarejos e cidades do interior do país com seus aparatos. Muitos levavam cenários 
para compor as imagens e anunciavam os serviços nos classificados dos jornais locais. A novidade despertava o interesse e a curiosidade dos populares. A autora salienta que, para muitos, esta era uma das únicas oportunidades de serem fotografados, pois uma grande parcela da população não tinha dinheiro nem condições de viajar aos grandes centros.

Durante a segunda metade do século XIX alguns fotógrafos e também estúdios alcançaram fama e contribuíram para a difusão da técnica no Brasil. A maioria dos profissionais eram estrangeiros e trabalhavam nos grandes centros. Os portugueses José Christiano de Freitas Henriques Junior, Joaquim Isley Pacheco e José Ferreira Guimarães, os alemães Revert Henry Klumb e Alberto Henschel e os suíços Georges Leuzinger e Guilherme Gaensly estão nesta lista. Entre os brasileiros destacam-se Marc Ferrez e Valério Vieira.

$\mathrm{O}$ ato de ir aos estúdios fotográficos possibilitou a perpetuação da própria imagem. Com o passar do tempo, a fotografia tornou-se uma forma de imortalizar aquilo que não deveria ser esquecido. Deste modo, em contraposição, o que não é (era) fotografado não pode (podia) ser comprovado, por isso cai (caía) no esquecimento.

\section{Presença dos negros nos estúdios fotográficos}

Sandra Koutsoukos trabalha nesta publicação com imagens de pessoas negras escravas, forras e livres. Os registros dos escravos são subdivididos em outras três categorias: fotografias de escravos domésticos; imagens exploradas como exóticas e vendidas como souvenirs a estrangeiros e fotografias etnográficas utilizadas como suporte para a propagação das teorias racistas.

A autora argumenta que os negros nascidos livres ou que alcançaram a liberdade antes da promulgação da Lei Áurea de 1888 (forros) eram comumente registrados à moda europeia. Tal feito era uma estratégia desta 
parcela da população para combater o preconceito e a discriminação racial, já que bem trajados e com elementos (anéis, chapéus e utensílios) da moda internacional vigente conseguiriam comprovar, imageticamente, que não eram escravos. Os indivíduos que possuíssem marcas de violência física tratavam logo de escondê-las. Os cabelos bem penteados, as roupas pomposas e os sapatos bem lustrados tinham a função social de afastálos da origem africana e da ascendência escrava. Tanto os adultos quanto as crianças eram retratados com suas melhores roupas e em poses sérias. A pesquisadora destaca que uma fotografia bem composta, no caso dos negros recém-libertos, poderia funcionar como um passaporte para a nova condição social em que o sujeito se enquadrava. Dessa forma, o negro livre deveria parecer livre em sua representação. Outra prática bastante comum neste período era caracterizar o ex-escravo no exercício de alguma função (como barbeiro ou cozinheiro). Desta forma, o indivíduo declarava-se livre e apto para o trabalho.

Entre as fotografias que registravam os cativos destacam-se as imagens de escravos domésticos levados por seus senhores para os estúdios. Estas representações, via de regra, iriam compor o álbum da família. O intuito era o de enfatizar o valor simbólico e o status social das imagens, já que os escravos eram propriedades dos seus senhores. As fotografias relatavam o poder dos senhores e a invisibilidade social dos escravos. Os cativos eram fotografados descalços, com roupas gastas ou rasgadas e, em alguns casos, com correntes atadas aos pés. A autora afirma que em registros construídos desta forma, o intuito do senhor não era o de documentar a personalidade de cada um de seus escravos, mas o de classificá-los como propriedade sua.

Ainda na categoria de escravos domésticos encontram-se também os registros das amas de leite (que amamentavam os filhos dos seus senhores) e amas-secas (que ajudavam na criação das crianças). Estas mulheres eram registradas de uma forma mais positiva que o restante dos cativos. De acordo com a análise desenvolvida, as amas ocupavam um lugar de confiança diante da família e privilegiado em relação aos outros escravos. Na maioria das vezes as mulheres eram fotografadas 
com trajes e acessórios à moda europeia e acompanhadas das crianças brancas.

As fotografias de negros na segunda metade do século XIX tiveram ainda duas outras formas de uso bastante difundidas: a fundamentação das teorias racistas e a venda como souvenirs para os turistas. O alemão Augusto Stahl registrou várias imagens etnográficas encomendadas pelo naturalista Louis Agassiz para embasarem seus estudos e comparações raciais. $\mathrm{O}$ intuito desses estudos era comprovar imageticamente a superioridade da raça branca e refutar a teoria evolucionista proposta por Charles Darwin. Estas fotografias encontram-se reunidas no Peabody Museum na Universidade de Harvard. Já as imagens com a função de representar os aspectos exóticos do país eram destinadas à comercialização. Muitos visitantes estranhavam o fato de o Brasil ser mantido por um sistema escravista na segunda metade do século XIX. As imagens tinham a missão de apresentarem um sistema de exploração, mas com características civilizadas.

No último capítulo do livro, a pesquisa trabalha com imagens de negros presidiários presentes em dois álbuns da Galeria de Condenados. $\mathrm{O}$ interessante destas fotografias é que elas foram tomadas por um presidiário que apreendeu a técnica durante o cárcere.

Em Negros no estúdio do fotógrafo: Brasil, segunda metade do século XIX, Sandra Sofia Machado Koutsoukos procurou estudar os vários sentidos e usos das representações desta parcela da população. A autora também focou a forma como os personagens se posicionavam frente à máquina e como influenciavam na composição da imagem.

O livro é uma leitura importante para interessados em fotografia e na história do Brasil. Com uma narrativa agradável e fluída, a autora apresenta os padrões de representação dos negros na segunda metade do século XIX, com fotografias, até então, pouco conhecidas. O trabalho é bastante completo, além de ser uma fonte relevante para pesquisas acadêmicas. 